
17-28.

\title{
Objectification strategies outperform subjectification strategies in military interventionist discourses
}

\author{
Christopher Hart (Lancaster University) \\ Matteo Fuoli (University of Birmingham)
}

\section{Introduction}

Politicians and other 'political speakers' must engage in discursive work to construct themselves and the claims they offer as 'reasons for action' as credible. This is particularly the case when the action being proposed is high-stakes and/or when audiences are generally sceptical. The discursive means available to political speakers in this regard have been investigated in pragmatics, social psychology and critical discourse analysis. Broadly, two competing strategies can be identified: subjectification versus objectification. Both strategies function to elevate the epistemic status of the proposition advanced, thereby strengthening the justificatory case for actions that is being made on the back of it. In this study, we use experimental methods to compare empirically the effectiveness of these two alternative strategies. We do so in the context of political discourse seeking sanction for military action. Illustrative examples in the Background section are taken from three texts produced by Tony Blair in the immediate run-up to military intervention in Iraq in 2003. It should be noted from the outset that our intention is not to aid politicians in the promotion of war by providing them with the most effective means of persuasion. On the contrary, we assume a critical stance and, in demonstrating the effectiveness of attested discursive practices, seek to further highlight the role that language plays in the exercise of power.

\section{Background}

The twenty-first century has seen Anglo-American-led military interventions in Afghanistan and Iraq. At the time of writing, another military action, this time against Iran, seems a distinct possibility. Going to war is a high-stakes political decision. Arguably, as van Dijk (2011: 53) suggests, it is one that "needs the most solid argumentation in a democratic state today". This is especially the case amidst a climate of scepticism in which the public doubt the motives of politicians (Ipsos MORI, 2017). Politicians seeking sanction for military actions must therefore do discursive work to convince audiences - both members of parliament and the public - that a case has been made and that a decision in favour of military action is justified. Discourses justifying recent military actions have been widely studied in critical discourse analysis (Cap 2006; Chilton 2005; Dunmire 2011; Marín Arrese 2011; Reyes 2011; van Dijk 2011). In the case of Iraq, for example, initial justifications were based on the claim that Saddam Hussein possessed weapons of mass destruction and that he therefore posed a physical threat to people living in Western countries (Cap 2006). However, when it became clear that Saddam Hussein did not, in fact, have access to weapons of mass destruction, justifications for war with Iraq shifted to become more ideologically based with the regime at the time being constructed instead as a threat to the beliefs and values of democratic societies (ibid.). Whether physical or ideological, these threat claims are used as premises in arguments aimed at justifying military 'interventionist' actions (in order to neutralise the threat presented). The arguments are based on the speaker's assumption that his or her audience will be more likely to approve pre-emptive military actions if the threat presented is construed as personally consequential (Cap 2011: 82). However, in order for the argument to be 
This is a pre-proof version. For citation, consult final published version in Journal of Pragmatics 162: 17-28.

convincing, assuming that the conclusion is warranted by the premise, the premise itself must be believed. Political speakers must therefore do further discursive work to justify their claims to truth as much as normative rightness. As Chilton (2004: 23) states:

Political discourse involves, among other things, the promotion of representations, and a pervasive feature of representation is the evident need for political speakers to imbue their utterances with evidence, authority and truth, a process that we shall refer to in broad terms, in the context of political discourse, as 'legitimisation'. ${ }^{1}$

Based on Sperber's theory of epistemic vigilance (Sperber 2000, 2001; Sperber et al. 2010), Chilton $(2004,2005)$ argues that such epistemic legitimisation is necessary in political discourse because audiences are naturally disposed toward distrust. From an evolutionary perspective on communication, Sperber reasons that audiences must be vigilant against the risks of misinformation and, in order to minimise those risks, before accepting any incoming message as true, perform a series of checks directed at both text-internal factors like the logical consistency of the message and textexternal factors like the credibility of the speaker and/or the evidentiary bases of their claims. In political discourse, Chilton therefore argues, "political speakers have to guard against the operation of their audience's 'cheater detectors' and provide guarantees for the truths of their sayings" (2004: 23). The linguistic resources through which epistemic legitimisation is realised belong to the functional semantic categories of epistemic modality and evidentiality (Hart 2011; see also Bednarek 2006). Indeed, these aspects of language can be seen as having evolved precisely to fulfil the function of trust-attainment (Sperber et al. 2010).

A key variable in epistemic legitimisation is the discursive construction of authority, conceptualised in terms of credibility, reliability, integrity etc. Van Leeuwen (2007) distinguishes between different types of authority, including personal authority and expert authority. In the case of personal authority, authority is vested in a person by virtue of their role or status within a particular institution (p. 94). According to van Leeuwen, such authorities need not invoke any justification for their claims beyond 'because I say so' (ibid.). Their personal authority is reason enough for audiences to accept the claim as true. In the political domain, personal authority is displayed by the fact that "politicians stand as authoritative sources, presenting information in a formal context, producing official and institutional discourse" (Reyes 2011: 786; see also Martin Rojo and van Dijk 1997: 530). Expert authority is based on expertise rather than status. It is displayed in political discourse when external voices, recognised as expert within a given domain, are brought into the discourse either in support of the speaker's claim or as the basis for their claim (van Leeuwen 2007: 94-5; see also Reyes 2011: 800-1). In both cases, epistemic legitimisation lies in "the speaker's claim to have better knowledge, recognition of the 'real' facts" (Chilton 2004: 117).

Broadly, two types of epistemic legitimisation can be identified, which overlap with personal versus expert authority respectively: subjectification versus objectification (Hart 2010, 2011). In subjectification, the speaker, in effect, asks the audience to take their word for the veracity of the proposition advanced (Hart 2011: 759). Objectification, by contrast, puts on display the speaker's means of knowing and in so doing suggests that their assertion can be verified or that it is corroborated

\footnotetext{
${ }^{1}$ The term 'legitimisation' is often used in a more general way to capture the various processes by which speakers seek license or accreditation for a type of social behaviour (Reyes 2011: 782). Chilton (2004) distinguishes between epistemic and deontic legitimisation. We use the term here in the more restricted sense of epistemic legitimisation conceived as "a linguistic strategy involved in the legitimisation of assertions, a necessary move in the discursive legitimisation of actions" (Hart 2011: 752).
} 
This is a pre-proof version. For citation, consult final published version in Journal of Pragmatics 162: 17-28.

by others (ibid.). The terms subjectification and objectification have their origins in Lyons (1977) who distinguished between subjective and objective modalities. According to Lyons, in the case of objective modality, the speaker's assertion is based on some quantifiable fact or knowledge, which is presented alongside the proposition, whereas, in the case of subjective modality, the speaker merely expresses his or her opinion. The distinction is illustrated in the following example from van Dijk (2014: 276): "we may express our subjective belief or impression that it will soon start to rain (e.g. looking at the sky etc.) or objectively predict this on the basis of external expert evidence such as the weather report".

It should be noted that subjectification and objectification are not absolute categories but exist instead as idealisations on a cline of subjectivity, which also takes in intersubjectivity and represents the degree to which the speaker is the lone source of the claim. In a fully subjectified utterance, the speaker is the sole source and may be identified as such explicitly or only implicitly. In a fully objectified utterance, it is not the speaker but some third party that is identified as the ultimate source of the claim (which, of course, the speaker is making too through the voice of the third party). An additional, related facet of subjectivity addressed by Marín Arrese (2011) concerns the degree of responsibility that the speaker takes for the communicated proposition and whether or not this is shared with others. In a fully subjectified utterance, the speaker assumes personal responsibility for the claim being made while at the opposite end of the continuum, attributions serve to shift at least part of the responsibility onto third-party sources. Somewhere in between are utterances indicating shared or collective responsibility. Such utterances include expressions of intersubjectively shared knowledge or beliefs, e.g. via second person cognitive verbs (we all know ...). They also include suggestions of some evidentiary basis for the claim that is, while ultimately grounded in the speaker's subjectivity, at least potentially intersubjectively accessible, e.g. through cognitive and communicative evidentials (that means ..., that suggests ...) or perceptual evidentials (it seems ..., it is clear ...) which, as Sanders and Spooren (1996: 246) note, signal that "commitment to the validity of the information is shared or at least potentially shared by the speaker/listener and other participants".

The distinction between epistemic modality and evidentiality, similarly, is not clear-cut. Different classifications have been offered in which the two categories are seen to intersect in different ways and to enter into different relations of sub- and super-ordination (e.g. Aikhenvald 2004; Cornillie 2009; de Haan 1999; Givón 1982; Nuyts 2001; Palmer 1986; Willett 1988). From a discourse perspective, however, the demarcation of these domains and their hierarchical organisation is less significant and it is preferable to see them both in relation to the broader phenomena of epistemological positioning (Bednarek 2006) or the construction of epistemological stance (Mushin 2001)

The majority of research into epistemic modality and evidentiality has been of a semantic, morphological and typological nature (Mushin 2013). In the case of evidentiality, since English has no closed system for the marking of evidence, this has resulted in a near-total exclusion of English from the research into evidentiality (Bednarek 2006: 636). However, as Mushin (2013) points out, there is now increasing interest in non-grammaticalised evidential constructions as markers of epistemic authority and responsibility, including in political discourse (e.g. Fetzer 2008, 2014; Furko 2017), where "speakers are motivated to adopt a particular epistemological stance partially on the basis of their source of information, but also on the basis of their rhetorical intentions, on how they want their utterance to be understood and treated in the moment of the interaction" (Mushin 2001: 58). From a critical or rhetorical perspective, evidentials may therefore be studied as part of the "more elaborate discursive and interactional strategies of persuasively showing the sources, methods, reasons or arguments that show the validity of information and reliability of speakers" (van Dijk 2014: 274). 
This is a pre-proof version. For citation, consult final published version in Journal of Pragmatics 162: 17-28.

In political discourse, then, as in all domains of natural-language communication, speakers do more than just express propositions; they provide reasons for hearers to accept communicated propositions as true or valid. Such reasons may be predicated on the personal authority of speakers themselves in subjectification or on the authority of expert sources and other external evidentiary bases in objectification.

Linguistically, subjectification and objectification are realised across a range of different forms. For example, modal verbs (could, may, will) and zero-marked modality as in (1) ground an assertion in the speaker's own subjectivity and display different levels of epistemic commitment toward the truth of the proposition.

(1) The threat posed to international peace and security ... is real. (Blair, 2002)

The role of the speaker as evaluator, however, remains implicit. While the evaluation is grounded in the speaker's own subjective assessment, there is no explicit appeal to their personal authority as a reason to believe the claim being made. In explicit subjectification, by contrast, the speaker explicitly asks the audience to trust in their knowledge or opinion. As Marín Arrese (2011: 215) puts it, the speaker becomes an "explicit point of reference" in the epistemic judgement. Examples of explicit subjectification are found in matrix clauses that feature a first person subject + mental-state predicate in the main clause, which takes scope over the proposition expressed in the complement clause. This includes cognitive verbs (I believe ..., I know ...) and personal predicates (I am certain that ..., I am convinced that ...). Explicit subjectifications are also found in adverbial phrases that explicitly reference the speaker's role as evaluator (For me ..., In my judgement ...).

Choices made with respect to these devices have important implications for the texturing of political identities and may be subject to situational constraints. Thus, questions raised by Fetzer (2008: 386) are "to what extent political agents make use of these devices, and in what contexts they choose to self-reference with a cognitive verb, thereby making their cognitive states public, and when they choose to attribute particular cognitive states to others". In a study of political speeches justifying military intervention in Iraq, Marín Arrese (2011) found explicit subjectifications to be a marked feature in the discourse of Tony Blair (as compared to the discourses of George W. Bush and José María Aznar). The following examples are all taken from texts produced by Blair in the lead-up to military intervention in Iraq. They are suggestive of a speaker confident enough in their own credibility to draw on it and offer their personal assessment as a reason to believe the claim.

(2) Let me tell the house what I know. I know that there are some countries or groups within countries that are proliferating and trading in WMD, especially nuclear weapons technology. ! know there are companies, individuals, some former scientists on nuclear weapons programmes, selling their equipment or expertise. I know there are several countries - mostly dictatorships with highly repressive regimes - desperately trying to acquire chemical weapons, biological weapons or, in particular, nuclear weapons capability. (Blair, 2003a)

(3) I am in no doubt that the threat is serious and current, that he has made progress on WMD. (Blair, 2002)

(4) I am quite clear that Saddam will go to extreme lengths, indeed has already done so, to hide these weapons and avoid giving them up. (Blair, 2002)

(5) And the possibility of the two coming together - of terrorist groups in possession of WMD, even of a so-called dirty radiological bomb is now, in my judgement, a real and present danger. (Blair, 2003a) 
This is a pre-proof version. For citation, consult final published version in Journal of Pragmatics 162: 17-28.

(6) My judgment, as prime minister, is that this threat is real, growing and of an entirely different nature to any conventional threat to our security that Britain has faced before. (Blair 2003b)

Fetzer (2008: 388) points out that by using parantheticals like I think, I believe and I know, the speaker is not just making known the basis for their assertion, they are persuading the hearer to adopt his or her perspective towards the claim being made. Explicit subjectifications such as found in (2) - (6) will be most persuasive when the speaker has vested in them sufficient authority that 'their word' carries epistemic weight. Moreover, in such contexts, since explicit subjectifications indicate that the speaker/writer personally subscribes to the assessment (Marín Arrese 2011: 214), speakers risk reputational damage in the future should their assessment turn out to be wrong. Explicit subjectifications may therefore be convincing based on the assumption that speakers vested with personal authority would not wish to take such risks unless they were confident in the validity of their claim.

In discourses aimed at justifying controversial actions, where there is likely to be some level of opposition or scepticism, it is essential that the assessment of the situation on which the case for action is being built is not just a personal one but represents a legitimate conclusion born of credible evidence (van Dijk 2011: 54). A characteristic feature of most political discourse is therefore the incorporation of objectification strategies. As van Dijk (2011: 53) states, "speakers are more credible when they are able to attribute their knowledge or opinions to reliable sources, especially if some of the recipients may doubt whether they are well grounded". In objectifications, then, the speaker evidences their claim either by grounding it in the subjectivity of an external source, who the audience can be presumed to trust, or by marking it as having been discerned from some kind of objective evidence. Here, we can distinguish between attributions and what Bednarek (2006) calls based averrals.

In attributions, the speaker attributes the claim to some third-party source - as something they have either said or thought. Linguistically, attributions are therefore realised in instances of reported speech or reported thought - expressed in a matrix clause involving a third-person subject + verbal or mental-state predicate in the main clause, which assumes scope over the proposition contained in the complement clause. In the case of reported speech, in written texts, the claim often appears inside quotation marks (Reyes 2011: 800). Attributions perform an epistemic legitimising function when the source is someone in whom institutionalised authority is vested (van Leeuwen and Wodak 1999: 104) and who the audience can therefore be expected to regard as reliable. In such instances, attributions evoke a voice of expertise which is brought into the here-and-now context of the current speech event to endorse the claim ultimately being made by the speaker (Reyes 2011: 800). In effect, in attributing claims to third-party sources, the speaker offers a guarantor for the truth of the proposition (Hart 2011: 763). At the same time, attributions have the effect of diffusing responsibility for the claim and thus sharing blame with the voices of expertise brought into the discourse should the claim later turn out to be false (Martin Rojo and van Dijk 1997: 536; Reyes 2011: 800). Van Dijk (2011) analysed in detail the 18 March 2003 speech given to parliament by Tony Blair and found the main source relied upon to be the United Nations, its weapons inspectors and its Security Council. Examples of reported speech are given in (7) and (8).

(7) UN weapons inspectors say vast amounts of chemical and biological poisons, such as anthrax, $V X$ nerve agent, and mustard gas remain unaccounted for in Iraq. (Blair, 2003a)

(8) On 7 March, the inspectors published a remarkable document. It is 173 pages long, detailing all the unanswered questions about Iraq's WMD. It lists 29 different areas where they have been unable to obtain information. For example, on VX it says: "Documentation available to 
This is a pre-proof version. For citation, consult final published version in Journal of Pragmatics 162: 17-28.

Unmovic suggests that Iraq at least had had far reaching plans to weaponise VX". (Blair, 2003a).

In based averrals the claim remains grounded in the subjectivity of the speaker as the source of the claim. This may be made explicit or left implicit. However, some objective evidence is explicitly identified as the basis for the claim. Attributions and based averrals are similar to one another in both form and function such that a gradience can be perceived between them (Bednarek 2006: 647). Functionally, for example, both are part of the same phenomenon, evidentiality (ibid.), where based averrals, like attributions, can be used "argumentatively ... to provide backing or support for a statement" (Bednarek and Caple 2012: 151). There is also a perceived similarity of structure in their surface-level syntactic realisation (Bednarek 2006: 647). Consider the examples in (9) and (10) which represent an attribution versus a based averral respectively.

(9) [T]he document discloses that his military planning allows for some of the WMD to be ready within 45 minutes of an order to use them. (Blair, 2002)

(10) Intelligence reports make clear that he sees the building up of his WMD capability, and the belief overseas that he would use these weapons, as vital to his strategic interests, and in particular his goal of world domination. (Blair, 2002)

The distinction between attributions and based averrals lies in the fact that while attributions are based on what other speakers/sensers have said or thought (HEARSAY vS MINDSAY), based averrals "give some sort of indication about the evidential basis of the writer's averral without attributing propositions to an Other" (Bednarek 2006: 647).

In political discourse, the evidential bases in based averrals typically take the form of independent reports, studies, documents etc. from which 'facts' can be read or inferred. Thus, the same sources that feature in attributions may feature as bases in based averrals, as in the examples above. Lists and statistics are also particularly important here and are frequently appealed to in support of epistemic claims (Chilton 2004: 117; van Dijk 2000: 222). Based averrals, then, are subjective in the sense that they are "premised on the writer's interpretation of data" (Bednarek 2006: 647). However, they are more objective than the mere expression of opinion. They mark the proposition as being based on some sort of 'hard proof' (Bednarek 2006: 640) which, potentially at least, is intersubjectively accessible. By making their means of knowing explicit in based averrals, the speaker therefore makes it possible, in principle, for the claim to be verified. In effect the speaker suggests that, given the evidence, the hearer would arrive at the same conclusion. In practice, however, in political contexts the hearer seldom has direct access to the evidentiary basis on which the speaker's claim is predicated and must therefore ultimately still trust in the speaker themselves. Part of the personal authority that a political speaker constructs for themselves, then, as seen in (11) and (12), is a claim to have privileged access to evidence.

(11) We cannot, of course, publish the detailed raw intelligence. I and other Ministers have been briefed in detail on the intelligence and are satisfied as to its authority ... What I believe the assessed intelligence has established beyond doubt is that Saddam has continued to produce chemical and biological weapons, that he continues in his efforts to develop nuclear weapons, and that he has been able to extend the range of his ballistic missile programme. (Blair, 2002)

(12) My fear, deeply held, based in part on the intelligence that I see, is that these threats come together and deliver catastrophe to our country and world. (Blair, 2003b) 
This is a pre-proof version. For citation, consult final published version in Journal of Pragmatics 162: 17-28.

In summary of this section, two epistemic legitimising strategies are open to political speakers: subjectification versus objectification. Explicit subjectification strategies appeal to the personal authority of the speaker as a reason to accept the claim being made. Objectification strategies, by contrast, appeal to the authority of others or else make known the evidentiary basis of the claim in order to convince audiences of its validity. In this paper, we compare empirically the effectiveness of these two alternative strategies and specifically the use of explicit subjectifications versus based averrals in the context of a proposed military intervention. We predict that explicit subjectifications will be more effective in persuading audiences to support military intervention than objectifications in contexts where the speaker's credibility is high and they are therefore able to rely on their own reputation as a trusted and reliable source. Conversely, we hypothesise that when the speaker's credibility is compromised, objectifications will be more effective since the speaker can no longer rely solely on their personal authority and must instead provide evidence in support of their claim. These hypotheses are explicitly formulated as follows:

H1: When the politician's credibility is high, subjectification strategies will lead to greater levels of support for military intervention than objectification strategies.

H2: When the politician's credibility is low, objectification strategies will lead to greater levels of support for military intervention than subjectification strategies.

In order to test these hypotheses, we ran an experiment using a $2 \times 2$ factorial design with credibility (high versus low) and epistemic legitimisation strategy (subjectification versus objectification) as independent variables.

\section{Method}

\subsection{Participants}

Participants were a convenience sample of 279 individuals recruited from staff and student populations at two universities in the United Kingdom and via the online recruiting platforms 'Call For Participants' (https://www.callforparticipants.com/) and r/SampleSize (https://www.reddit.com/r/SampleSize/). 60.57\% percent of the subjects were female, $38.35 \%$ were male and 1.08\% left their gender unspecified. Age ranged from 16 to 73 years ( $M=29.6, S D=13.7$ ). $64.52 \%$ of the sample identified as 'student', $24.73 \%$ as 'worker' and $10.75 \%$ did not indicate their current occupation. The majority of the participants were of British nationality $(70.97 \%)$, with the remaining reporting other nationalities, including Chinese, American and Japanese. $78.49 \%$ percent of the subjects were native speakers of English. Among the non-native speakers, the mean self-reported ability to understand English was 8.61 (SD = 1.79) on a scale ranging from 'poor' (1) to 'excellent' (10).

\subsection{Materials and design}

The experiment used a $2 \times 2$ between-subjects design with credibility (high vs. low) and legitimisation strategy (subjectification vs. objectification) as independent variables. Control variables included in the experiment were attitudes to war in general, generalised trust in politicians, and political orientation. The experiment was administered online using the survey platform Qualtrics. It involved four main steps, as shown in Fig. 1. 
This is a pre-proof version. For citation, consult final published version in Journal of Pragmatics 162: 17-28.

Figure 1. Experimental procedure

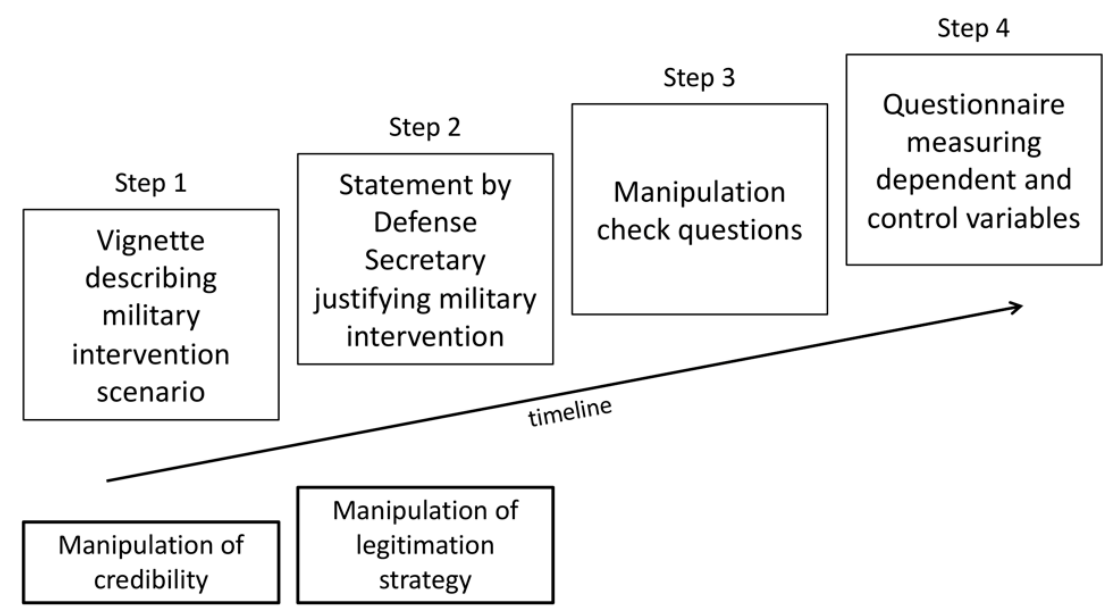

Participants were randomly assigned to one of the four experimental conditions. After receiving instructions and completing a consent form, they were presented with two short texts, each designed to manipulate one of the independent variables. The first text was a short vignette describing a scenario in which a prominent political figure, the Defense Secretary, is portrayed as a leading proponent of military action against the fictitious country of Dacrela in response to its leader's alleged human rights violations. Two versions of the vignette were created. The low credibility version reported that the Defense Secretary held shares in oil companies with an interest in Dacrela and that he had previously been accused of misleading the public over foreign policy issues. The text therefore suggested that the Defense Secretary's credibility was compromised by a conflict of interest and as a result of past misdeeds. In the high credibility version, the Defense Secretary was praised for their success in leading humanitarian missions and for their work with international charities. The text therefore increased the credibility of the Defense Secretary by presenting them as benevolent rather than motivated by self-interest. The two versions of the vignette were identical except for the last sentence, which contained the manipulation. An imaginary country was used in order to minimize the influence of participants' attitudes toward similar past cases (e.g. the Iraq war).

Participants were subsequently shown a statement by the Defense Secretary justifying the need for military intervention in Dacrela. Two different versions of this statement were created incorporating an explicit subjectification and a based averral, respectively. The statements are reproduced below, with the manipulations underlined.

I truly believe that the leader of Dacrela is guilty of horrific human rights violations. He must be stopped now. [subjectification strategy]

International intelligence reports prove beyond doubt that the leader of Dacrela is guilty of horrific human rights abuses. He must be stopped now. [objectification strategy]

In the subjectification condition, the justificatory claim is grounded solely in the subjective assessment of the Defense Secretary by means of the first-person subject + mental state predicate I believe, which takes scope over the proposition. The adverb truly further emphasizes the Defense Secretary's commitment to the proposition. In the objectification strategy condition, the justificatory claim is 
This is a pre-proof version. For citation, consult final published version in Journal of Pragmatics 162: 17-28.

presented as based on external evidence in the form of international intelligence reports. The claim is introduced by the evidential verb prove, which entails inductive reasoning based on evidence (Chafe 1986) and indexes certainty of knowledge (Biber and Finegan 1989). The evidential basis on which the claim rests is construed as publicly verifiable and therefore relatively objective (Bednarek 2006). The booster beyond doubt (Hyland 2005) serves to further enhance the epistemic force of the statement.

To encourage participants to read the stimuli materials carefully, the vignette and the statement were displayed for a minimum of 20 and 15 seconds, respectively, before participants could move forwards through the experiment. Participants were instructed not to use the 'back' button in their web browser as this would end the experiment. This was to ensure they did not re-read the texts in light of the follow-up questions. The materials are provided in Appendix 1.

After reading the stimulus texts, participants were presented with two manipulation check items tapping into their perceptions of the Defense Secretary's credibility and their interpretation of the Defense Secretary's statement. These items were used to verify that participants had read the texts carefully and that the manipulations had been successful. Lastly, participants completed a questionnaire comprising measurement scales for the dependent and control variables as well as a series of demographic questions relating to age, gender, nationality and language abilities (see Measures). The experiment concluded with a debriefing message which informed respondents that the scenario presented in the survey was fictitious, thanked them for their participation and invited them to enter a draw for an incentive prize.

\subsection{Measures}

Dependent and control variables were measured using scales drawn from previously-validated instruments. Support for military intervention was measured using five items adapted from the 'Attitude toward the Afghanistan War' and 'Attitude toward the Iraq War' scales used by Cohrs et al. (2005). Attitudes to war in general were assessed with five items drawn from the 'Generalized Militaristic Attitude' scale developed by Cohrs et al. (2005). Generalized trust in politicians was measured on a five-item scale derived from Mutz and Reeves (2005). For each item just described, scales were seven-point Likert scales with anchors 'strongly disagree' (1) and 'strongly agree' (7). Political orientation was assessed via a seven-point semantic-differential scale taken from Kehn and Ruthig (2013). The manipulation check items were 'Sound moral principles seem to guide the Defense Secretary's behaviour', for credibility, and 'The Defense Secretary's justification for military action in Dacrela is based on reliable evidence', for legitimisation strategy. Both statements were assessed on a seven-point Likert scale anchored at 'strongly disagree' and 'strongly agree'. All the items and scales used are given in Appendix 2.

\section{Results}

\subsection{Descriptive statistics and reliabilities}

Before submitting the results to statistical analysis, we assessed the quality of the data based on the manipulation checks. We initially considered excluding responses that exceeded the scale midpoint in the opposite direction to the one intended. Applying these criteria, however, would have resulted in the loss of over $20 \%$ of the data points, thus potentially compromising random assignment (Foschi 2014: 264). We therefore decided to apply a more conservative threshold and to only exclude participants whose scores on the manipulation checks were diametrically opposed to those expected, i.e. at the extreme ends of the scale in the opposite direction, and which were, thus, unequivocally 
This is a pre-proof version. For citation, consult final published version in Journal of Pragmatics 162: $17-28$

unreliable. So, for example, we discarded data points where participants had indicated that they 'strongly agree' with the first manipulation check item in the 'low credibility' condition. After these exclusions, a total of 257 cases were available for analysis.

Table 1 reports overall mean values, reliabilities, and inter-correlations of the dependent and control variables. As shown in the table, the Cronbach $\alpha$ scores for all the multi-item scales used were above the recommended cut-off of 0.70 (Nunally 1978).

Table 1. Variable means, standard deviations, reliabilities, and intercorrelations

\begin{tabular}{lllllll}
\hline Variable & $M$ & SD & $\alpha$ & 1 & 2 & 3 \\
\hline (1) Support for military intervention & 4.09 & 1.07 & 0.74 & & & \\
(2) Attitudes to war & 3.58 & 1.26 & 0.80 & $0.48^{*}$ & & \\
(3) Generalized trust in politicians & 2.99 & 1.02 & 0.82 & $0.13^{*}$ & $0.17^{*}$ & \\
(4) Political orientation & 2.93 & 1.52 & n.a. & $0.17^{*}$ & $0.47^{*}$ & $0.17^{*}$ \\
\hline${ }^{*}<<.05$. & & & & & &
\end{tabular}

Table 2 displays mean values and standard deviations for the dependent variable across experimental conditions. Mean scores across conditions are also presented graphically in Figure 2 to facilitate interpretation. The descriptive statistics suggest that, contrary to our expectations, the objectification strategy was more persuasive than the subjectification strategy regardless of the politician's credibility. In the next section, we examine whether these differences are statistically significant and test the hypotheses outlined above.

Table 2. Number of observations, means, and standard deviations by condition

\begin{tabular}{cccc}
\hline & & \multicolumn{2}{c}{ Support for military intervention } \\
\cline { 3 - 4 } & $\mathrm{N}$ & $\mathrm{M}$ & $\mathrm{SD}$ \\
\hline Low credibility & & & 1.09 \\
Objectification & 65 & 4.19 & 1.15 \\
Subjectification & 72 & 3.87 & \\
High credibility & & & 1.06 \\
Objectification & 55 & 4.32 & 0.96 \\
Subjectification & 65 & 4.06 &
\end{tabular}


This is a pre-proof version. For citation, consult final published version in Journal of Pragmatics 162: 17-28.

Figure 2. Variable means by experimental condition

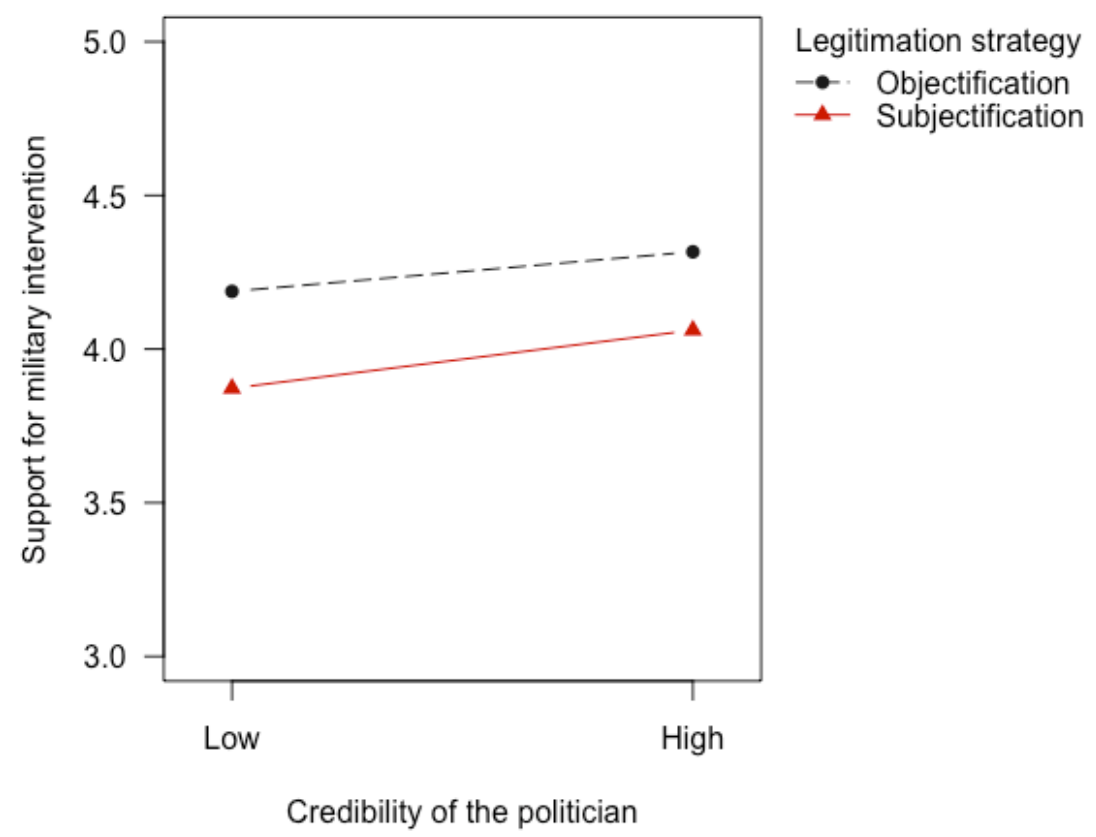

\subsection{Test of hypotheses}

Multiple regression analysis was used to assess main and interaction effects of credibility and legitimisation strategy on support for military intervention, controlling for attitudes to war, generalized trust in politicians and political orientation. Deviation coding was used for both independent variables. Prior reputation was coded -0.5 for positive and +0.5 for negative, while legitimation strategy was coded -0.5 for subjectification and +0.5 for objectification. $P$ values equal to or lower than .05 were considered statistically significant. The complete results of the analysis are presented in Table 3.

Table 3. Results of multiple regression analysis of independent and control variables on support for military intervention

\begin{tabular}{llll}
\hline Variable & $\beta$ & $t$ value & $p$ \\
\hline Credibility (high) & 0.01 & 0.23 & 0.815 \\
$\begin{array}{l}\text { Strategy } \\
\text { (objectification) }\end{array}$ & 0.13 & 2.39 & 0.017 \\
$\begin{array}{l}\text { Credibility * } \\
\text { legitimation strategy }\end{array}$ & 0.01 & 0.21 & 0.836 \\
$\begin{array}{l}\text { Attitudes to war } \\
\begin{array}{l}\text { Generalized trust in } \\
\text { politicians }\end{array}\end{array}$ & 0.51 & 8.16 & $<0.001$ \\
$\begin{array}{l}\text { Political orientation } \\
\text { Note. } \mathrm{N}=257, \text { Multiple } \mathrm{R}^{2}=0.26, \text { Adjusted } \mathrm{R}^{2}=0.24, \mathrm{~F}(6,250)=14.57, p<.001\end{array}$
\end{tabular}


This is a pre-proof version. For citation, consult final published version in Journal of Pragmatics 162: $17-28$.

Hypothesis 1 predicted that, when the politician's credibility is high, the subjectification strategy would be more effective in eliciting support for military intervention than the objectification strategy. While mean levels of support for military intervention were higher for subjectification strategies in the high credibility condition compared to the low credibility condition (see Figure 2), the difference is relatively small and statistically unreliable. Credibility had no significant effect on respondents' judgements and the interaction between credibility and legitimisation strategy is not significant. This hypothesis is therefore not supported.

Hypothesis 2 predicted that, when the politician's credibility is low, the objectification strategy would be more effective than the subjectification strategy. As shown in Table 3, this was indeed the case and hypothesis 2 is therefore confirmed. However, as the results of the regression analysis show, the objectification strategy had a significant and positive main effect on support for military intervention. That is, objectification outperformed subjectification regardless of credibility.

Among the control variables, only attitudes to war had an effect on the dependent variable. As expected, the more supportive of war as a solution to international conflicts participants were, the more inclined they were to also support the proposed military intervention in the experimental scenario.

\section{Discussion and Conclusion}

Political communication seems inherently to require that utterances are imbued with evidence and authority in order that the propositions they express are treated by audiences as true and can thus function effectively as premises in arguments for action. Such a process of epistemic legitimisation comes in at least two forms: explicit subjectifications involving an appeal to the speaker's own personal authority and objectifications involving an appeal to other expert sources or external evidentiary bases. We hypothesised that appeals to personal authority in the form of explicit subjectifications would be more effective than objectifications when the credibility of the speaker was high while, conversely, in contexts of low speaker credibility, objectification would be the more effective strategy. Our reasoning was that in an era of personalised politics (Langer 2012) and charismatic authority (Weber 1968), in the right epistemic conditions, the speaker's own evaluation would count for more than objective evidence. And that in such conditions, the need to rely on external evidence might even be taken to betray a lack of conviction and thus undermine the claim being made. Conversely, in situations where the speaker's credibility is compromised, the speaker's own judgement would carry little weight and audiences would accept claims only on the basis of external support.

Contrary to our hypotheses, however, the results indicate that the speaker's reputation as a credible source is of comparatively little concern to audiences and that what really counts is evidence supporting the validity of the claim. In epistemic vigilance terms, it is evidence rather than reputation that functions as the most reliable text-external index of trustworthiness and, when presented in discourse, is most likely to satisfy hearers' cognitive safeguards against misinformation. This, perhaps, is suggestive of some rank-order to the persuasiveness of epistemic legitimising strategies which corresponds with the degree of subjectivity involved, whereby the more subjectified the utterance, the less convincing the claim (Hart 2011: 760). To properly investigate this, however, would require further extensive empirical research which takes account of a wider range of epistemic legitimising strategies, including intersubjectifications involving appeals to perception, general knowledge or popular opinion and obviousness. 
This is a pre-proof version. For citation, consult final published version in Journal of Pragmatics 162: 17-28.

Of course, such a hierarchy of persuasiveness may not be fixed or universal but situationally dependent. We have only investigated the rhetorical effectiveness of these two epistemic legitimising strategies in a single restricted context. In other cultural and discursive environments, the credibility of the speaker may matter more than objective evidence. Consider, for example, the domain of religion. In the realm of politics, the greater weight attached to evidence than reputation can be interpreted against the backdrop of widespread mistrust in politicians (only $6 \%$ of people in five European countries say they have a great deal of trust in their government and the number of people who think politicians are not at all, or not very, honest outweighs those who disagree by $89 \%){ }^{2}$ This level of distrust is reflected in our data where the average generalised trust in politicians was low at 2.99/7. In a climate of scepticism, then, in which politicians of all stripes are distrusted, individual credibility or personal authority is less significant. Instead, as van Dijk (2014: 269) observes, in order to convince audiences that the claims they proffer in justification of proposed actions are well founded, political speakers "must make sure that their own discourse is based on reliable sources, modes or methods of knowledge acquisition and that such be made persuasively obvious to recipients".

From a critical standpoint, this does not make the claim true; only (superficially) more convincing. Evidence can be misinterpreted, deliberately or otherwise, and the authority attributed to third-party sources may be misplaced (as in the ad verecundiam fallacy). In the case of the Iraq war, of course, the intelligence used as evidence in arguments seeking sanction for military intervention turned out to be flawed.

In this experiment, we have shown that the mere citation of evidence (International intelligence reports prove beyond doubt that ...), regardless of the credibility of the speaker, is sufficient to elevate the epistemic status of the proposition and thus positively influence support for action which it is claimed to justify. Oswald and Hart (2014: 4) argue that in such instances "the cognitive system has not found it relevant to question the evidence provided". The fact that objectification strategies are successful, at least relative to subjectification strategies, suggests that, in the context of argumentative discourse, we may need to refine or recalibrate our epistemic safeguards so as to subject the presentation of evidence itself to greater scrutiny.

At this point, it is worth noting that although the objectification strategy outperformed the subjectification strategy across credibility conditions, the level of support it garnered was still relatively low, with a mean value of 4.25 , and the effect size, though significant, was relatively small (Cohen's $f^{2}=0.02$; the mean value across conditions for subjectification strategies was 3.96 ). Of greater import was prior attitudes to war, which had a stronger effect than the discursive strategy (Cohen's $f^{2}=0.27$ ). The more participants felt military intervention was an appropriate solution to international conflicts in general, the more inclined they were to support military intervention in the experimental scenario.

In line with previous experimental research in critical discourse analysis (e.g. Fuoli and Hart 2018; Hart $2018 \mathrm{a} / \mathrm{b}$ ), then, this highlights the need to take account of non-linguistic factors when measuring textual influence. Tentatively, it seems as though when participants are presented with more localised events, such as a particular political protest or a specific instance of corporate wrongdoing, they are more susceptible to the influence of textual choices. However, when the case in question hinges on much broader, ongoing and highly publicised, issues such as immigration or military interventions, prior opinions play a more prominent role and have the potential to override any putative effects of the immediate discourse (of course, that prior knowledge or opinion, can, in many circumstances, only

\footnotetext{
${ }^{2}$ https://image.guardian.co.uk/sys-files/Guardian/documents/2011/03/13/Guardian_Euro_Poll_day1.pdf
} 
This is a pre-proof version. For citation, consult final published version in Journal of Pragmatics 162: 17-28.

have been derived from or developed in opposition to other discourses). In such cases, it is possible that readers draw on the mental models (van Dijk 2014) they have for comparable past situations and use these to scaffold their knowledge and opinions with respect to present target situation. Again, further empirical research would be required to confirm this emerging picture.

Notwithstanding the need to take account of non-linguistic factors like prior knowledge and opinions, the experiment reported here contributes to the growing body of evidence empirically demonstrating the power that language has to influence social perceptions and thus pave the way for otherwise controversial actions. What is of note here is that is it not the semantic content or framing of a proposition or the type of speech act that has been shown to have an influence but differences in interpersonal aspects of communication, namely epistemological positioning.

\section{References}

Aikhenvald, A. (2004). Evidentiality. Oxford: Oxford University Press.

Bednarek, M. (2006). Epistemological positioning and evidentiality in English news discourse: A textdriven approach. Text \& Talk 26 (6): 635-660.

Bednarek, M. and Caple, H. (2012). News Discourse. London: Bloomsbury.

Biber, D., and Finegan, E. (1989). Styles of stance in English: Lexical and grammatical marking of evidentiality and affect. Text-interdisciplinary journal for the study of discourse, 9(1), 93-124.

Cap, (2006). Legitimisation in Political Discourse. Newcastle: Cambridge Scholars Publishing.

Chilton, P. (2004). Analysing Political Discourse: Theory and Practice. London: Routledge.

Chilton, P. (2005). Missing links in mainstream CDA: Modules, blends and the critical instinct. In R. Wodak and P. Chilton (eds.), A New Research Agenda in (Critical) Discourse Analysis: Theory and Interdisciplinarity. Amsterdam: John Benjamins. pp. 19-52.

Cornillie, B. (2009). Evidentiality and epistemic modality: On the close relationship between two different categories. Functions of Language 16 (1): 44-62.

Cohrs, J. C., Moschner, B., Maes, J., \& Kielmann, S. (2005). Personal values and attitudes toward war. Peace and Conflict, 11(3), 293-312.

de Haan, F. (1999). Evidentiality and epistemic modality: Setting boundaries. Southwest Journal of Linguistics 18 (1): 83-101.

Dunmire, P. (2011). Projecting the Future through Political Discourse. Amsterdam: John Benjamins.

Fetzer, A. (2008). 'And I think that is a very straight forward way of dealing with it': The communicative function of cognitive verbs in political discourse. Journal of Language and Social Psychology 27 (4): 384-396.

Fetzer, A. (2014). I think, I mean and I believe in political discourse: Collocates, functions and distribution. Functions of Language 21 (1): 67-94.

Foschi, M. (2014). Hypotheses, operationalizations, and manipulation checks. In M. Webster and J. Sell (eds.), Laboratory Experiments in the Social Sciences. Amsterdam, Elsevier. pp. 247-266. 
This is a pre-proof version. For citation, consult final published version in Journal of Pragmatics 162: 17-28.

Fuoli, M. and Hart, C. (2018). Trust-building strategies in corporate discourse: An experimental study. Discourse \& Society 29 (5): 514-552.

Furko, P. (2017). Manipulative uses of pragmatic markers in political discourse. Palgrave Communications 3: 17054.

Givón, T. (1982). Evidentiality and epistemic space. Studies in Language 6 (1): 23-49.

Hart, C. (2010). Critical Discourse Analysis and Cognitive Science: New Perspectives on Immigration Discourse. Basingstoke: Palgrave.

Hart, C. (2011). Legitimizing assertions and the logico-rhetorical module: Evidence and epistemic vigilance in media discourse on immigration. Discourse Studies 13 (6): 751-769.

Hart, C. (2014). Discourse, Grammar and Ideology: Functional and Cognitive Perspectives. London: Bloomsbury.

Hart, C. (2018a). Event-frames affect blame assignment and perception of aggression: An experimental case study in CDA. Applied Linguistics 39 (3): 400-421.

Hart, C. (2018b). 'Riots Engulfed the City': An Experimental Study Investigating the Legitimating Effects of Fire Metaphors in Discourses of Disorder. Discourse \& Society 29 (3): 279-298.

Hyland, K. (2005). Metadiscourse: Exploring interaction in writing. London \& New York: Continuum.

Ipsos MORI (2017). Veracity Index 2017.

https://www.ipsos.com/sites/default/files/ct/news/documents/2017-11/trust-in-professionsveracity-index-2017-slides.pdf. Accessed 18.09.2019.

Kehn, A., \& Ruthig, J. C. (2013). Perceptions of gender discrimination across six decades: The moderating roles of gender and age. Sex Roles, 69(5-6), 289-296.

Langer, A.I. (2012). The Personalisation of Politics in the UK: Mediated Leadership from Attlee to Cameron. Manchester: Manchester University Press.

Lyons, J. (1977). Semantics (2 vols). Cambridge: Cambridge University Press.

Marín Arrese, J. (2011). Effective vs. epistemic stance and subjectivity in political discourse: Legitimising strategies and mystification of responsibility. In C. Hart (ed.), Critical Discourse Studies in Context and Cognition. Amsterdam: John Benjamins. pp. 193-224.

Martin Rojo, L. and van Dijk, T.A. (1997). There was a problem, and it was solved! Legitimating the expulsion of 'illegal' immigrants in Spanish parliamentary discourse. Discourse \& Society 8 (4): 523-567.

Mushin, I. (2001). Evidentiality and Epistemological Stance: Narrative Retelling. Amsterdam: John Benjamins.

Mushin, I. (2013). Making knowledge visible in discourse: Implications for the study of linguistic evidentiality. Discourse Studies 15 (5): 627-645.

Mutz, D. C., \& Reeves, B. (2005). The new videomalaise: Effects of televised incivility on political trust. American Political Science Review, 99(1), 1-15.

Nunnally, J.C. Psychometric Theory. McGraw-Hill, New York (1978).

Nuyts, J. (2001). Epistemic Modality, Language and Conceptualization. Amsterdam: John Benjamins. 
This is a pre-proof version. For citation, consult final published version in Journal of Pragmatics 162: 17-28.

Oswald, S. and C. Hart (2014). Trust based on bias: Cognitive constraints on source-related fallacies. In D. Mohammed \& M. Lewiński (eds.), Virtues of Argumentation. Proceedings of the 10th International Conference of the Ontario Society for the Study of Argumentation (OSSA). Windsor, ON: OSSA, pp. 1-13.

Palmer, F. (1986). Mood and Modality. Cambridge: Cambridge University Press.

Reyes, A. (2011). Strategies of legitimization in political discourse: From words to actions. Discourse \& Society 22 (6): 781-807.

Sanders, J. and Spooren, W. (1996). Subjectivity and certainty in epistemic modality: A study of Dutch epistemic modifiers. Cognitive Linguistics 7 (3): 241-264.

Sperber, D. (2000). Metarepresentations in an evolutionary perspective. In D. Sperber (ed.), Metarepresentation: A Multidisciplinary Perspective. New York: Oxford University Press. pp. 117-138.

Sperber, D. (2001). An evolutionary perspective on testimony and argumentation. Philosophical Topics 29: 401-413.

Sperber, D., Clément, F. Heintz, C., Mascaro, O., Mercier, H., Origgi, G. and Wilson, D. (2010). Epistemic vigilance. Mind and Language 25 (4): 359-393.

Van Dijk, T.A. (2000). The reality of racism: On analysing parliamentary debates on immigration. In G. Zurstiege (ed.), Festschrift. Für die wirklichkeit. Wiesbaden: Westdeutscher Verlag. pp. 211226.

Van Dijk, T.A. (2011). Discourse, knowledge, power and politics: Towards critical epistemic discourse analysis. In C. Hart and P. Cap (eds.), Contemporary Critical Discourse Analysis. London: Bloomsbury. pp. 27-64.

Van Dijk, T.A. (2014). Discourse and Knowledge: A Sociocognitive Approach. Cambridge: Cambridge University Press.

Van Leeuwen, T.A. (1997). Legitimation in discourse and communication. Discourse \& Communication 1 (1): 91-112.

Weber, M. (1968). On Charisma and Institution Building. Chicago: University of Chicago Press.

Willett, T. (1988). A crosslinguistic survey of grammaticalization of evidentiality. Studies in Language 12: 51-97. 
This is a pre-proof version. For citation, consult final published version in Journal of Pragmatics 162: $17-28$.

\section{Data sources}

Blair, T. (2002). Foreword to the 'September dossier' Iraq's Weapons of Mass Destruction: The Assessment of the British Government. http://news.bbc.co.uk/nol/shared/spl/hi/middle east/02/uk dossier on $\mathrm{iraq} / \mathrm{html} /$ full dossi er.stm\#foreword

Blair, T. (2003a). Speech opening debate on the Iraq crisis in the House of Commons. $18^{\text {th }}$ March. https://api.parliament.uk/historichansard/commons/2003/mar/18/iraq\#S6CV0401PO 20030318 HOC 138

Blair, T. (2003b). Televised address to the nation. $21^{\text {st }}$ March. http://news.bbc.co.uk/1/hi/uk politics/2870581.stm

\section{Appendix 1. Experimental stimuli}

\section{Initial vignette}

Low credibility version.

The government is currently considering military intervention in Dacrela, a country whose leader is alleged to be guilty of human rights abuses. One of the most vocal proponents for going to war against Dacrela is the Defense Secretary. However, the Defense Secretary is known to hold shares in oil companies with an interest in Dacrela and has previously been accused of misleading the public over foreign policy issues.

High credibility version.

The government is currently considering military intervention in Dacrela, a country whose leader is alleged to be guilty of human rights abuses. One of the most vocal proponents for going to war against Dacrela is the Defense Secretary. The Defense Secretary has lead a number of successful humanitarian missions in the past and is known for his work with international charities.

\section{Defense Secretary's statement}

Subjectification condition

The Defense Secretary has issued the following statement justifying the need for military intervention: "I truly believe that the leader of Dacrela is guilty of horrific human rights violations. He must be stopped now."

\section{Objectification condition}

The Defense Secretary has issued the following statement justifying the need for military intervention: "International intelligence reports prove beyond doubt that the leader of Dacrela is guilty of horrific human rights abuses. He must be stopped now." 
This is a pre-proof version. For citation, consult final published version in Journal of Pragmatics 162: 17-28.

\section{Appendix 2. Scales and manipulation checks}

SUPPORT FOR MILITARY INTERVENTION (adapted from Cohrs et al. 2005)

1. It would be justified to take military action against Dacrela.

2. Under no circumstances should the country go to war against Dacrela. $(r)$

3. Dacrela should be forced to accept United Nations monitoring-if necessary by military means.

4. If necessary, the leader of Dacrela should be brought down with military force.

5. I firmly reject the military intervention in Dacrela. ( $r$ )

ATTITUDES TO WAR (adapted from Cohrs et al. 2005)

1. Our state should spend much less on armaments. ( $r$ )

2. War is an indispensable means to solve international conflicts.

3. War is a crime against life and therefore morally reprehensible. ( $r$ )

4. War is never justified. ( $r$ )

5. Threat of military force is often the best way to keep down aggressive states.

GENERALIZED TRUST IN POLITICIANS (adapted from Mutz and Reeves 2005)

1. Politicians generally have good intentions.

2. When politicians make statements on television or in the newspapers, they are usually telling the truth.

3. Most politicians can be trusted to do what is right.

4. Despite what some people say, most politicians try to keep their campaign promises.

5. Most politicians do a lot of talking but they do little to solve the really important issues facing the country. $(r)$

Manipulation checks (from 1 (strongly disagree) to 7 (strongly agree))

1. Sound moral principles seem to guide the Defense Secretary's behavior.

2. The Defense Secretary's justification for military action in Dacrela is based on reliable evidence. 